\title{
BILATERAL EPIBULBAR DERMOIDS WITH ISOLATED DEXTROCARDIA- A RARE CASE WITH REVIEW OF LITERATURE OF CARDIOVASCULAR MALFORMATIONS IN GOLDENHAR SYNDROME
}

\author{
Shobhana Dube ${ }^{1}$, Salil Dube ${ }^{2}$, Pratyush Ranjan ${ }^{3}$ \\ ${ }^{1}$ Associate Professor, Department of Ophthalmology, Career Institute of Medical Sciences and Hospital, Lucknow, U. P. \\ ${ }^{2}$ Associate Professor, Department of Community Medicine, Maharaja Agrasen Medical College, Agroha, Haryana. \\ ${ }^{3}$ Senior Consultant, Department of Ophthalmology, NSPB, Shaheed Bhagat Singh Eye Hospital, Bareilly, U. P.
}

ABSTRACT

\section{BACKGROUND}

Goldenhar syndrome (Oculo-auriculo-vertebral dysplasia) is a condition comprising of triad of Ocular, Otic and Vertebral anomalies. It is also associated with multiple malformations involving Heart, Lungs and Kidneys. Congenital Heart Disease has been reported in 5\% - 58\% of patients with Goldenhar syndrome. The most common reported cardiovascular malformations are Ventricular Septal Defects and Tetralogy of Fallot.

\section{CONCLUSION}

Isolated dextrocardia has never been reported as association of Goldenhar syndrome. The genetic loci responsible for Goldenhar syndrome still remains elusive, more specific and rare associations will help detect that. To the best of our knowledge, this remains the first reported case of isolated Dextrocardia with bilateral and unusual presentation of Limbal Dermoids in Goldenhar syndrome.

\section{KEYWORDS}

Goldenhar Syndrome, Dextrocardia, Cardiac Anomalies.

HOW TO CITE THIS ARTICLE: Dube S, Dube S, Ranjan P. Bilateral epibulbar dermoids with isolated dextrocardia- a rare case with review of literature of cardiovascular malformations in Goldenhar syndrome. J. Evolution Med. Dent. Sci. 2017;6(64):4680-4683, DOI: $10.14260 /$ Jemds/2017/1012

\section{BACKGROUND}

Goldenhar Syndrome is a condition featuring ocular abnormalities (Epibulbar dermoid or lipodermoids, unilateral microphthalmia and upper eyelid coloboma), otic anomalies (Microtia, low set ears, auricular appendages and/or blindended fistulas) and vertebral anomalies (Atlas occipitalisation, synostosis, hemivertebrae, fused vertebrae, scoliosis and bifid spine).

Principal deformities of Goldenhar syndrome are often combined with cardiovascular malformations, digital abnormalities, central nervous system disorders, lung disorders and urogenital anomalies.

Cardiovascular malformations have been reported in 5\% $58 \%$ of patients with Goldenhar syndrome. ${ }^{1}$ Tetralogy of Fallot and ventricular septal defects are the most common cardiac anomalies reported and agenesis of the internal carotid artery is one of the more common vascular anomalies. $^{2-5}$ Dextrocardia has been reported rarely and always as a part of complex cardiac anomalies. ${ }^{6-8}$

We are reporting a case of isolated dextrocardia with no symptoms arising due to it. All patients with Goldenhar syndrome must undergo cardiac evaluation to rule out any cardiac anomaly.

Financial or Other, Competing Interest: None.

Submission 03-07-2017, Peer Review 31-07-2017,

Acceptance 03-08-2017, Published 10-08-2017.

Corresponding Author:

Dr. Shobhana Dube,

R/O. 1/35, HIG,

Vikas Nagar, Near Pioneer School,

Lucknow-226022, Uttar Pradesh.

E-mail: shobhanadube@gmail.com

DOI: $10.14260 /$ jemds $/ 2017 / 1012$

\section{Introduction}

A 3-year-old female child presented to us with complaints of protruding mass in right eye and discoloured mass in left eye. According to the patient's father, this mass was small in size at birth and it kept on increasing in size with age, attaining the present size. General examination of the patient revealed an undernourished child. She had symptoms of respiratory tract infection. Vitals of the patient were stable. She was the youngest of the three children and product of term gestation delivered by spontaneous vertex to a 22 -year-old mother in a non-consanguineous marriage. There was no history of febrile illness, ingestion of drugs, diabetes, smoking or any exposure to irradiation during pregnancy. The labour and delivery were uneventful. Apart from ocular abnormality, no other major problem was seen during neonatal period. There was no history of feeding difficulties, but occasional common cold symptoms and mild respiratory distress was noted. Respiratory examination revealed fine crepts. Cardiovascular examination suggested dextrocardia. ENT examination revealed preauricular appendages with mild conductive deafness. Examination of Central Nervous system, Gastrointestinal system and Orthopaedic examination revealed no abnormalities.

Lab investigations revealed Microcytic hypochromic anaemia and neutrophilia.

Ophthalmic Examination showed poor fixation. Retinoscopy of right eye was $+2 \mathrm{D}$ in both axes, while in left eye it was $+1.75 \mathrm{D}$ in both axes. There was no corneal astigmatism. Right eye revealed a stump of approximately 10 $\mathrm{mm}$ in length and $8.6 \mathrm{~mm}$ in breadth protruding laterally. This stump was emanating from near the temporal limbus, but not involving the cornea which explains absence of corneal astigmatism. The stump had hairy appendages on its surface. Ocular movements were full; however, there was deficiency of lateral canthus. Cornea, Iris, Pupil and Lens was normal. 
Left eye examination revealed an epibulbar dermoid of approximately $0.5 \mathrm{~cm}$ near the temporal limbus. Apart from this, other structures in left eye were normal. USG B-scan of both eyes revealed lid echoes due to the epibulbar dermoids of size $10 \times 8.6 \mathrm{~mm}$ on right side. Posterior chamber, optic nerve and retrobulbar tissues were normal on both sides. There was no deeper penetration of the epibulbar dermoids on both sides [Fig. 1].

Ultrasound of abdomen and pelvis was normal [Fig. 2]. Xray chest PA view revealed ill-defined opacities in left lower lung suggesting infective lesions. Also, the bulk of the heart was noted on the right side suggestive of dextrocardia [Fig. 3A and 3B]. There was no other abnormality detected.

$\mathrm{X}$-ray dorsolumbar spine AP and lateral views revealed no abnormalities. Ultrasound of Abdomen and Pelvis showed no abnormality. No abnormality was detected in MRI cranium.

MRI orbit revealed evidence of well-defined fat intensity lesions (on all sequences) noted on lateral aspect of right eye suggestive of likely dermoid cyst. No evidence of any other soft tissue intensity lesion was present. Though, isolated dextrocardia was present, no other functional abnormality of heart was detected. 2D Echo/ M mode/ Doppler PW and CW/ Colour flow imaging report revealed ejection fraction of $74 \%$ with normal cardiac valves and intact septum [Fig. 4A and 4B]. Patient was advised excision of the dermoid of the right eye with repair of lateral canthus and amniotic membrane transplantation on the bare area of sclera.

\section{Discussion with review of Literature of Cardiovascular Malformations in Goldenhar Syndrome}

Goldenhar syndrome is a malformation complex of varying severity, involving the structures from the first and second branchial arches, the first branchial cleft and primordia of the temporal bone. Various hypotheses like chromosomal abnormalities involving 22q11 chromosomal loci, ${ }^{9}$ late gestation vascular disruptions, ${ }^{10}$ teratogenic drug exposure during pregnancy, ${ }^{11}$ environmental influences especially in gulf war veterans ${ }^{12}$ and maternal diabetes ${ }^{13,14}$ have been postulated to explain the spectrum of anomalies, but none seem to be conclusive at present. The disease is sporadic; family reports on occasion have suggested autosomal dominant or recessive inheritance, but at present aetiology can be best described as multifactorial with no clear pathway of its development.

This syndrome was first described by Canton in 1861 and again by Von Arlt in 1881, but it went largely unnoticed until 1952 when Maurice Goldenhar recorded 3 new cases in addition to the 16 previously recorded which gathered the attention of medical community and the condition was named after him. ${ }^{18}$ In 1963, Robert J Gorlin, a dentist and geneticist reviewed 40 cases reported up till that time calling it Oculoauriculovertebral dysplasia. For his pioneering work, it is also called Goldenhar-Gorlin syndrome. The Goldenhar syndrome was originally defined as a triad of congenital abnormalities consisting of epibulbar dermoid, preauricular appendages and pretagal fistulae. After Gorlin, the asymmetry of the face or hemifacial microsomia was also described as a usual association of this triad.

In 1952, Swiss Ophthalmologist, Maurice Goldenhar provided a comprehensive description of Oculoauricular dysplasia consisting of preauricular appendages, fistulas and epibulbar dermoids. Gorlin included vertebral anomalies as signs of the syndrome and suggested the name Oculoauriculovertebral dysplasia. Smith used the term facioauriculo-vertebral sequence to include both Goldenhar syndrome and hemifacial microsomia.

\section{In a Classic Goldenhar Syndrome Patient, Characteristic Clinical Findings include the Following: ${ }^{1}$}

- Epibulbar dermoid or lipodermoid (mostly bilateral), Colobomas of the upper eyelid, Iris, Choroidea and Retina or other eye anomalies (eg. microphthalmia, anophthalmia, cataract, astigmatism, antimongoloid obliquity of palpebral fissures and blepharophimosis).

- Preauricular skin tags or blind fistulas; microtia or other external ear malformations (dysplasias, asymmetries, aplasias and atresias of the external meatus); middle and internal ear anomalies.

- Unilateral facial hypoplasia, prominent forehead, hypoplasia of the zygomatic area and maxillary and mandibular hypoplasia.

- Unilateral macrostomia (Lateral facial cleft).

- Vertebral column anomalies (Atlas occipitalisation, synostosis, fused vertebrae, scoliosis and bifid spine.

Principal Deformities of the Goldenhar Syndrome are often combined with Various Malformations such as-

- Cleft lip and/or palate, tongue cleft, unilateral tongue hypoplasia and parotid gland aplasia.

- Rib anomalies and anomalies of the extremities.

- Congenital heart disease (Ventricular septal defects), anomalies of the urogenital and gastrointestinal system (ectopic kidneys, ureteropelvic junction obstruction and imperforate anus), anomalies of the central nervous system (occipital encephalocoele) and anomalies of the larynx and lungs (tracheo-oesophageal fistula, oesophageal atresia).

- Complex retardation of mental development.

The exact cause of Goldenhar syndrome is unknown, but considered to be multifactorial, i.e. a combination of gene interactions and environmental factors causes a maldevelopment of $1^{\text {st }}$ and $2^{\text {nd }}$ branchial arches during the first trimester of pregnancy. Environmental causes such as maternal diabetes during pregnancy, thalidomide, gestational or pre-existing vasoactive drugs, smoking and twinning indicating a multifactorial aetiology (environmental and genetic). One of the most favoured hypothesis is that of vascular disruption in vitro. $^{3}$

Males are more commonly affected than females (3:2). There is also a 3:2 ratio of right-sided versus left-sided involvement (Rollinck et al 1987). About $10 \%$ to $30 \%$ of patients have bilateral, usually asymmetrical microsomia. There is no agreement on the incidence of Goldenhar syndrome in the literature. Reports vary between 1:3000 to 1:5000 and 1: 25000 to 40000 .

Congenital heart defects are common and are reported to vary from $5 \%$ to $58 \%$ (Friedman and Saraclar 1974; Greenwood et al 1974; Gorlim et al 1976; Shokeir 1977; Pierpont et al 1982; Tenconi and Hall 1983; Wilson 1983; Rollinck et al 1987). 
Ventricular septal defect or Tetralogy of Fallot with or without a right aortic arch, accounts for about $50 \%$ of the defects, although no single cardiac lesion is characteristic.

Other anomalies may include transposition of the great vessels, tubular hypoplasia of the aortic arch associated with mild coarctation of aorta, isolation of left innominate artery with patent ductus arteriosus, pulmonic stenosis and dextrocardia. Hypoplasia of the external carotid artery and situs ambiguous has also been noted. ${ }^{2}$

Cardiovascular anomalies associated with Goldenhar syndrome were reported by Morisson et al in 1992.4

Nakajima et al ${ }^{5}$ reported multiple CVM malformations including Wolff-Parkinson white syndrome, partial anomalous pulmonary venous connections, PDA, anomalous origin of the coronary arteries and a right-sided descending aorta.

M Cristina Digilio et al $^{6}$ studied a series of 87 patients with Oculo-auriculo-vertebral syndrome (OAVS) and reported 32\% atrial and VSD, 39\% conotruncal defects, $14 \%$ targeted growth defects, $70 \%$ with situs and looping defects, $40 \%$ with a left-sided obstructive lesion and $4 \%$ with patent ductus arteriosus. In other series, most common cardiovascular malformations reported are Ventricular Septal Defect (VSD) and Tetralogy of Fallot.

Rad EM ${ }^{7}$ reported case of Goldenhar Syndrome (GHS) with right circumflex aortic arch, severe coarctation and vascular ring in a twin pregnancy.

Gorgu $\mathrm{M}$ et $\mathrm{al}^{8}$ reported GHS association with situs inversus totalis.

Dextrocardia is a congenital defect, in which heart is located on right side of the body. It was recognised in 1643 by Marco Severeno.

Dextrocardia is Congenital. There are two main types of Dextrocardia-

- Dextrocardia of embryonic arrest (also known as isolated dextrocardia).

- Heart is simply placed farther right in the Thorax than in normal individuals.

- Commonly associated with severe defects of the heart including abnormalities such as Pulmonary Hypoplasia.
In Isolated Dextrocardia, heart is healthy. The cause is unknown. It usually causes no symptoms and is detected usually when X-ray or MRI of chest is done. It occurs with equal frequency in males and females.

- Dextrocardia with situs inversus.

- It refers to Dextrocardia with situs inversus, in which the heart is a mirror image situated on the right side.

- $\quad$ For all visceral organs to be mirrored, the correct term is Dextrocardia situs inversus totalis.

- $\quad$ Although, persons with Dextrocardia situs inversus tend not to have any medical problems from the disorders. Some are prone to a number of Bowel, Oesophageal, Bronchial and Cardiac problems where some of the conditions can be lifethreatening if uncorrected.

- Approximately, $0.01 \%$ infants are born with this rare disorder. ${ }^{9}$

There have been reports of Dextrocardia with Situs inversus ${ }^{10,11,12,13,14}$ associated with GHS, but even after extensive search in literature we could not find a case of bilateral epibulbar dermoids presenting unusually and in association with Isolated Dextrocardia with normal heart functions. This is to our knowledge the first report with the above presentation making our case unique.

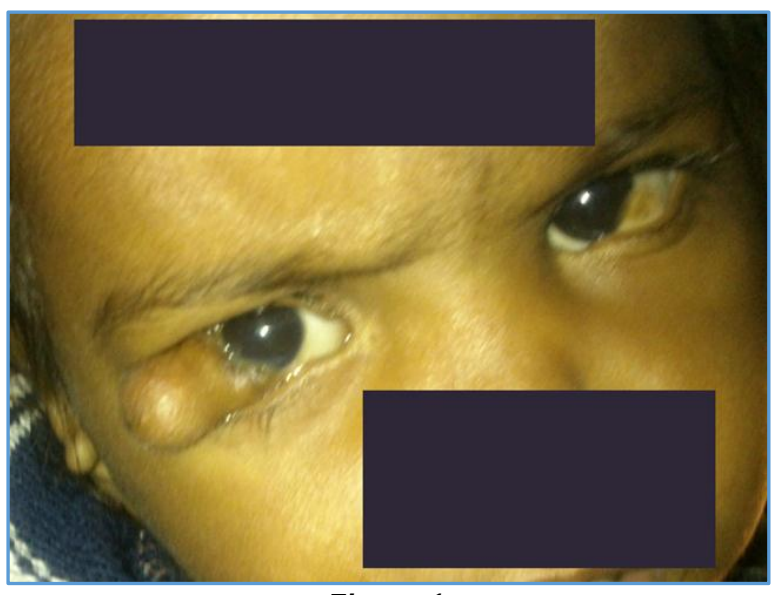

Figure 1

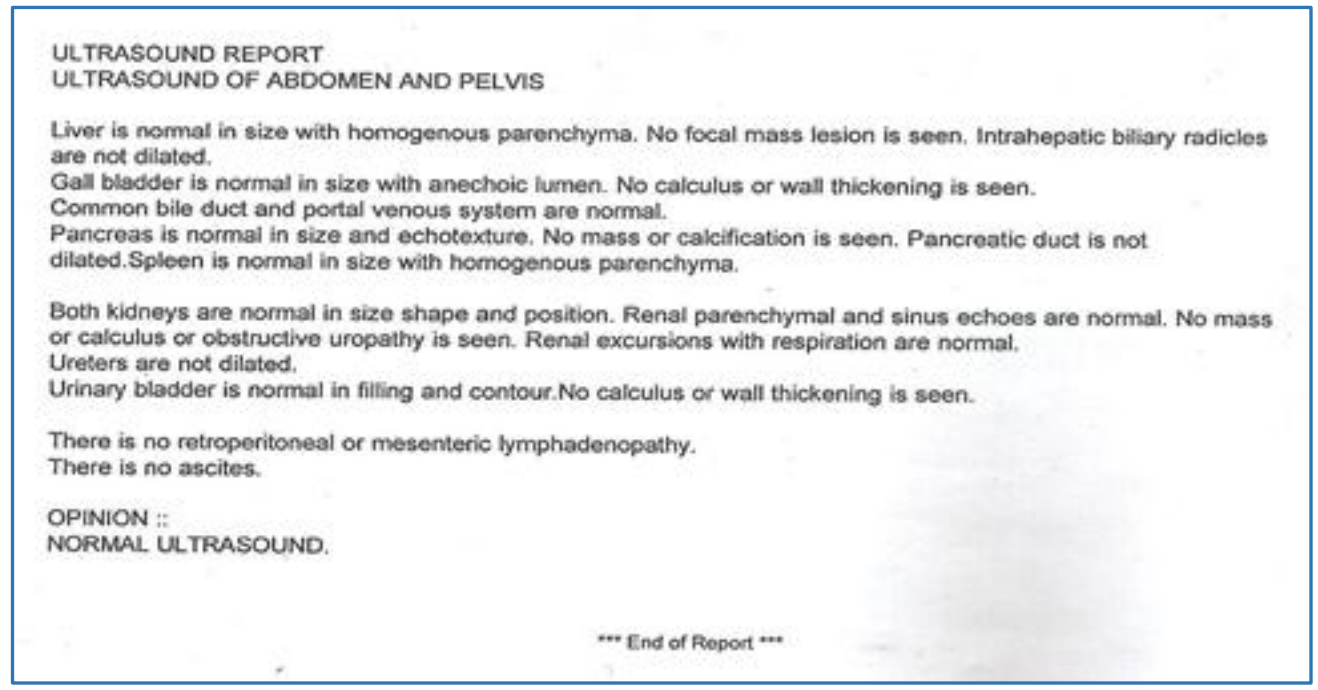

Figure 2. USG of Abdomen and Pelvis 


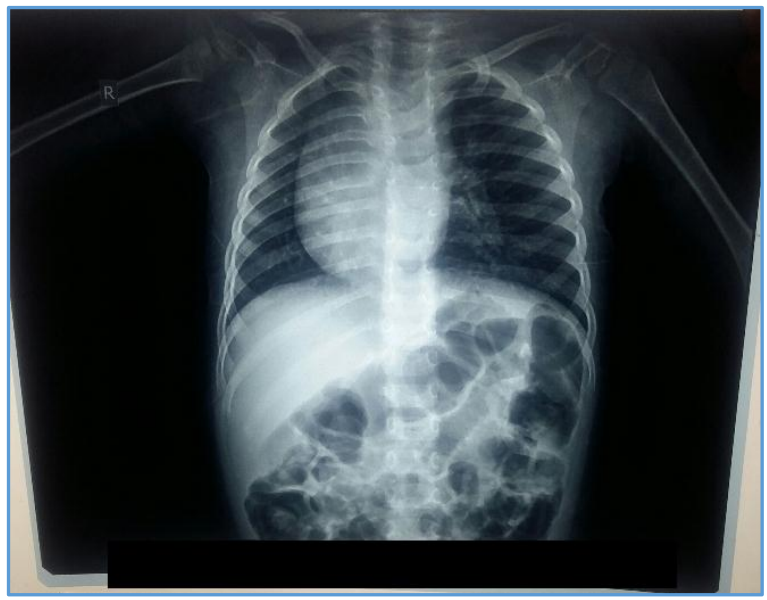

Figure 3-A. X-Ray Chest PA View

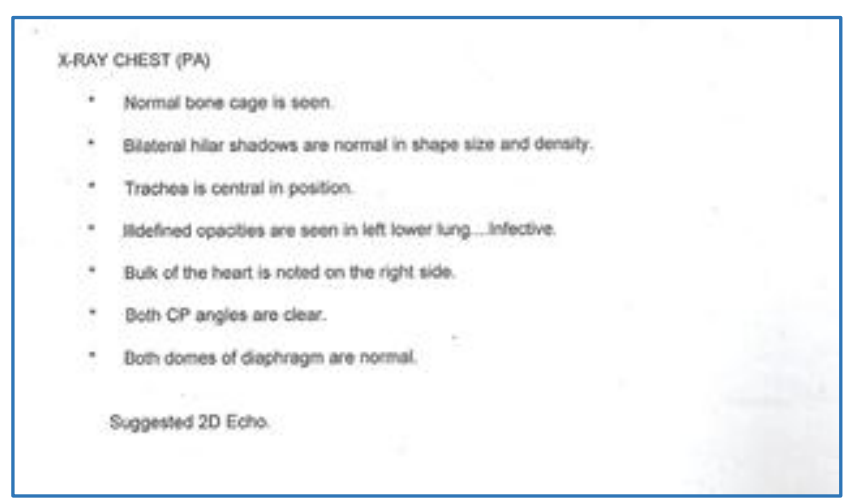

Figure 3-B

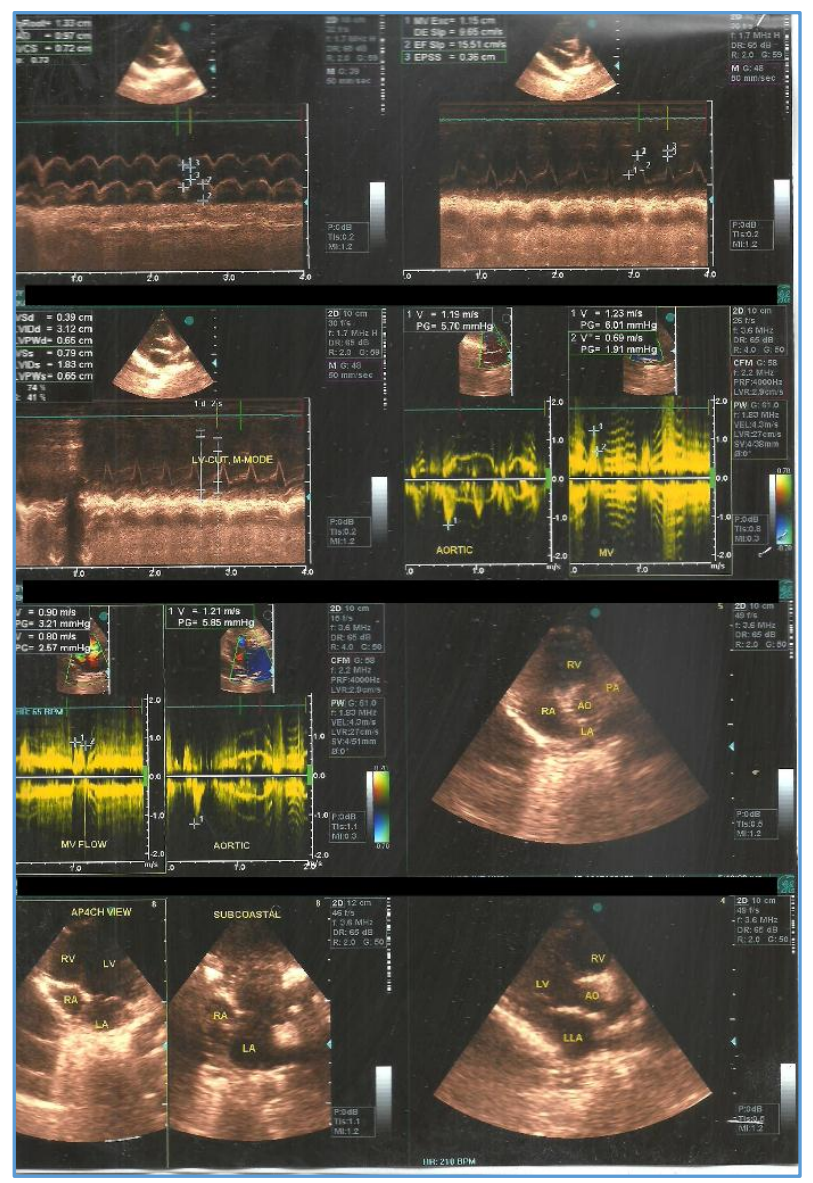

Figure 4-A. Echo and Cardiac Colour Doppler Imaging

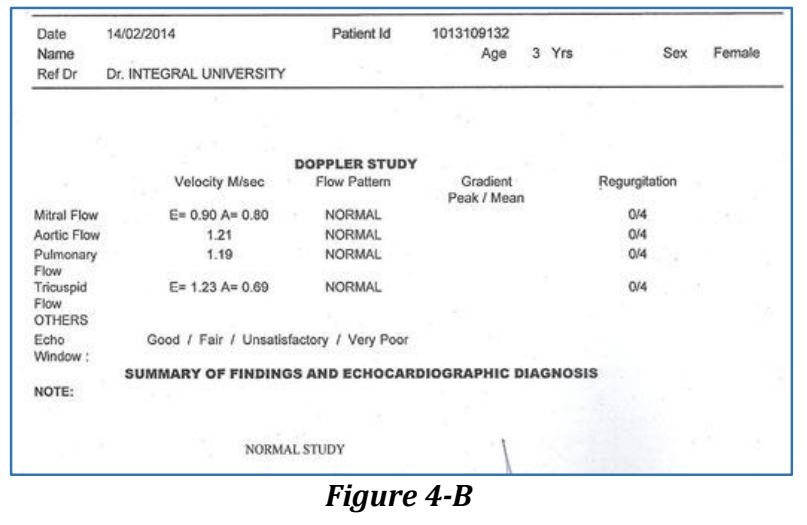

\section{REFERENCES}

[1] Kokavec R. Goldenhar syndrome with various clinical manifestations. Cleft Palate Craniofacial Journal 2006;43(5):628-34.

[2] Gorlin RJ, Cohen MM, Raoul CM. Syndromes of the head \& neck. $4^{\text {th }}$ edn. Hennekam Oxford University Press 2001.

[3] Meireles AB, Smith JC, Saraura JM, et al. Oculoauriculo-vertebral spectrum: a review of literature\& genetic update. J Med Genetics 2014;51(10):635-45.

[4] Morisson J, Mulholland HC, Craig BG, et al. Cardiovascular abnormalities in oculo-auriculovertebral spectrum. Am J Med Genetics 1992;44(4):425-28.

[5] Nakajima H, Goto G, Tanaka N, et al. Goldenhar syndrome associated with various cardiovascular malformations. Japanese Clinical Journal 1998;62(8):617-20.

[6] Digilio MC, Calzolari F, Capolino R, et al. Congenital Heart Defects in patients with Oculo-auriculovertebral spectrum. American Journal of Medical Genetics Part A 2008;146A(14):1815-9.

[7] Rad EM. Goldenhar syndrome with right circumflex aortic arch, severe coarctation and vascular ring in a twin pregnancy. Ann Pediatric Cardiol 2014;7(3):21720.

[8] Gorgu M, Aslan G, Erdooan B, et al. Goldenhar syndrome associated with situs inversus totalis. Int J Oral Maxillofacial Surgery 1998;27(5):404-6.

[9] Ekpe EE, Ikpe MC. Isolated dextrocardia coexisting with skeletal anomalies and mild cardiac anomalies. Nigerian Health Journal 2011;11(2).

[10] Kumar AP, Sasidharan V, Krishnan C. Situs inversus totalis with complex cardiac malformations in Goldenhar syndrome. Kuwait Medical Journal 2004;36(3):212-3.

[11] Vijayalakshmi P, Rao S, Chugh R. A comprehensive approach to congenital heart disease. $1^{\text {st }}$ edn. Jaypee Brothers Medical Publishers 2013.

[12] Mollen JH, Gorlin RJ, Edwards JE, et al. Congenital, cardiac, pulmonary, and vascular malformations in oculoauriculovertebral dysplasia. Pediatric Cardiol 1982;2(4):297-302.

[13] Greenwood RD, Rosental A, Sommer A, et al. Cardiovascular malformation in oculo-auriculovertebral dysplasia. Creanen J J Pediatr 1974;85: 816-8.

[14] Friedman S, Saraclar M. Letter: The high frequency of congenital heart disease in oculo-auriculo-vertebral dysplasia (Goldenhar's syndrome). J Pediatr 1974;85(6):873-4. 